\title{
Correction to: (Sex) Crime and Punishment in the \#MeToo Era: How the Public Views Rape
}

\author{
Susanne Schwarz ${ }^{1}$ Matthew A. Baum² . Dara Kay Cohen ${ }^{2}$
}

Published online: 25 September 2020

○) Springer Science+Business Media, LLC, part of Springer Nature 2020

\section{Correction to: Political Behavior https://doi.org/10.1007/s11109-020-09610-9}

The original version of this article mistakenly listed "the Foundations of Human Behavior Initiative at Harvard University" in Acknowledgements section. The proper acknowledgement is "the Pershing Square Fund for Research on the Foundations of Human Behavior at Harvard University".

Publisher's Note Springer Nature remains neutral with regard to jurisdictional claims in published maps and institutional affiliations.

The original article can be found online at https://doi.org/10.1007/s11109-020-09610-9.

Susanne Schwarz

susanneschwarz@princeton.edu

Matthew A. Baum

matthew_baum@hks.harvard.edu

Dara Kay Cohen

dara_cohen@hks.harvard.edu

1 Department of Politics, Princeton University, 001 Fisher Hall, Princeton, NJ 08544, USA

2 Harvard Kennedy School, 79 JFK Street, Cambridge, MA 02138, USA 